\title{
Meningoencefalite necrotizante de cão Maltês
}

\author{
Necrotizing meningoencephalitis of Maltese dog
}

\author{
Kalan Bastos Violin ${ }^{I}$ Nicolle Gilda Teixeira de Queiroz ${ }^{\mathrm{I}}$ Fernando Yutaka Moniwa Hosomi $^{\mathrm{I}}$ \\ Adriano Tony Ramos ${ }^{\mathrm{I}}$ Helena Arantes do Amaral ${ }^{\mathrm{II}}$ Márcia Mery Kogika ${ }^{\mathrm{II}}$ \\ Gisele Fabrino Machado ${ }^{\mathrm{I}}$ Paulo César Maiorka ${ }^{{ }^{*}}$
}

\begin{abstract}
A Meningoencefalite Necrotizante (MEN) é uma encefalopatia causada por uma disfunção inflamatória de característica necrotizante. $O$ objetivo deste relato é descrever os aspectos clínicos e anatomopatológicos da Meningoencefalite Necrotizante (MEN) em um cão Maltês. A doença tem um caráter necrótico único e está relacionada intimamente à Encefalite do Cão Pug (ECP) devido a suas semelhanças, bem como à Leucoencefalite Necrotizante (LEN). Embora o primeiro relato de caso de ECP tenha mais de 15 anos e o primeiro relato de caso de MEN em Maltês tenha 11 anos, há muito a ser revelado sobre a etiologia e os mecanismos imunopatológicos da doença. Neste trabalho, relata-se o caso de um cão Maltês com sinais que foram compatíveis com a MEN. Foram detectadas nas imagens macroscópicas, cavitação cerebral, e na microscopia, perda de células do parênquima em certas regiões do córtex cerebral. A partir dessas descobertas descrevese o primeiro caso de MEN em cão Maltês no Brasil.
\end{abstract}

Palavras-chave: meningoencefalite necrotizante, cão maltês, sistema nervoso central.

\section{ABSTRACT}

The Necrotizing Meningoencephalitis (NME) is an encephalopathy caused by an inflammatory dysfunction with necrotic characterization. The aim of this report is to describe the anatomopathological features of the NME in a Maltese dog. The disease has a unique necrotic pattern and is closely related to Pug Dog Encephalitis (PDE) because of their similarity as well as to Necrotizing Leukoencephalitis (NLE). Although the first PDE report has more than 15 years and the first Maltese NME report has 11 years there is a lot to be unveiled about the etiologic and the immunopathologic mechanisms of the disease. Here we report one case of a Maltese dog with signs that were compatible with NME. The gross morphology pictures with the cerebral cavitation and the histological loss of parenchymal cells in some regions of the cerebral cortex were detected. Based on these findings, we describe the first case of NME in Maltese dog in Brazil.

Key words: necrotizing meningoencephalitis, maltese dog, central nervous system.

A Meningoencefalite Necrotizante (MEN) é uma encefalopatia causada por uma disfunção inflamatória de caráter necrotizante, com etiologia ainda desconhecida, que foi inicialmente descrita em cães da raça Pug como a Encefalite do cão Pug (ECP) (BELTRAN \& OLLIVET, 2000; CORDY \& HOLLIDAY 1989; HINRICHS et al., 1996; KOBAYASHI et al., 1994; SUMMERS et al., 1995).

Cães de outras raças pequenas também podem ser acometidos por encefalopatias necrotizantes, visto que a doença MEN já foi relatada em cães das raças Maltês (STALIS et al., 1995) e Papillon (SUZUKI et al., 2003), além da doença Leucoencefalite Necrotizante (LEN) que foi relatada em cães das raças Pequinês (CANTILE et al., 2001) e Yorkshire Terrier (TIPOLD et al., 1993).

Na LEN, o tipo de lesão histológica se assemelha ao da ECP, diferenciando-se pela localização preferencial das lesões. Estas não ocorrem na substância cinzenta do córtex cerebral, mas sim no tronco encefálico (SCHATZBERG et al., 2005). Na MEN, a apresentação clínica, o diagnóstico por imagem e as lesões histopatológicas se assemelham à ECP. Os sinais

IDepartamento de Patologia, Faculdade de Medicina Veterinária, Universidade de São Paulo (FMVZ/USP). Av. Prof. Dr. Orlando Marques de Paiva, 87, 05508-900, São Paulo, SP, Brasil. E-mail: maiorka@usp.br. *Autor para correspondência.

IDepartamento de Clínica Médica, FMVZ/USP, São Paulo, SP, Brasil 
clínicos são caracterizados por crises convulsivas, andar compulsivo, ataxia e preferencialmente alterações de comportamento ligadas ao prosencéfalo (CORDY \& HOLLIDAY, 1989). A dilatação ventricular é freqüentemente observada no exame de Tomografia Computadorizada (BELTRAN \& OLLIVET, 2000; KUWABARA et al., 1998; STALIS et al., 1995; SUZUKI et al., 2003).

Por meio do exame necroscópico, podem ser visualizadas áreas pseudocísticas no córtex cerebral. Com a realização de cortes coronais, pode-se observar aumento ventricular, achatamento cortical e malácia.

No exame histopatológico, observa-se meningoencefalite não-supurativa, caracterizada principalmente, por sua natureza necrotizante, pela presença de manguitos perivasculares, microgliose, neuronofagia e evidência de intenso sofrimento neuronal, representado pelos neurônios fantasmas, envolvendo substância cinzenta e branca do córtex (CORDY \& HOLLIDAY, 1989, KOBAYASHI et al., 1994).

Neste relato de caso, descrevem-se os aspectos patológicos, macro e microscópicos, de um cão da raça Maltês com MEN que foi clinicamente avaliado no Hospital Veterinário da Faculdade de Medicina Veterinária e Zootecnia da Universidade de São Paulo (HOVET-FMVZ-USP). A cadela da raça Maltês, peso corpóreo de $2,7 \mathrm{~kg}$, com quatro anos de idade, não-castrada, com imunização atualizada, foi atendida no Serviço de Clínica Médica de Pequenos Animais do HOVET-FMVZ-USP por apresentar como principais sinais convulsões e andar compulsivo em círculos para direita. Conforme observado, os sinais iniciaram de forma súbita.

$\mathrm{O}$ animal foi submetido à terapia a base de prednisona ( $1 \mathrm{mg} \mathrm{kg}^{-1} \mathrm{dia}^{-1}$ ) e fenobarbital $\left(2 \mathrm{mg} \mathrm{kg}^{-1}\right)$ a cada 12 horas, ocorrendo a melhora parcial do quadro clínico com o controle das crises convulsivas e do andar compulsivo por um período aproximado de dois meses quando, então, o animal evoluiu para piora acentuada dos sinais neurológicos, com o comprometimento importante do estado mental. Devido à gravidade do quadro clínico e do mau prognóstico, o proprietário optou pela eutanásia do animal.

As alterações anatomopatológicas observadas restringiram-se ao Sistema Nervoso Central (SNC). Na avaliação macroscópica, após abertura do crânio, foi observado o espessamento da dura-máter. Após fixação e cortes coronais do encéfalo, foi observada assimetria dos hemisférios; o hemisfério esquerdo apresentava-se diminuído em relação ao hemisfério direito em que foi constatada presença de maior dilatação ventricular (Figura 1A) e um adelgaçamento do córtex em região parietal devido à compressão. No hemisfério esquerdo, detectou-se a presença de pseudocistos em córtex na região do lobo piriforme (Figura 1A, Figura 1B), em córtex temporal, constatou-se a perda de distinção entre a substância cinzenta e a substância branca em alguns pontos, como também a atenuação dos sulcos adjacentes. Na avaliação microscópica, foram observados manguitos perivasculares, espessamento das leptomeninges do encéfalo e presença de infiltrado mononuclear inflamatório no espaço leptomeningeal e nos vasos submeningeais. O córtex da área temporal e o lobo piriforme apresentaram áreas de necrose e cavitações repletas de conteúdo líquido e debris celulares (Figura1C), com pseudocisto medindo $5 \mathrm{~mm}$ de largura (Figura1D). Observou-se gliose difusa, satelitose, neuronofagia e neurônios fantasmas. Em destaque, visualiza-se a gliose difusa ao lado de uma área necrótica com envolvimento do córtex e leptomeninges (Figura1E). Na substância branca, cortical constatouse grande quantidade de macrófagos espumosos nas áreas de lesão (Figura 1F).

As manifestações clínicas foram inespecíficas, não sendo possível estabelecer o diagnóstico definitivo, bem como causa etiológica da doença. Em relação aos achados anatomopatológicos macroscópicos, observou-se que as lesões pseudocísticas se restringiam ao córtex cerebral, e na, região do lobo piriforme, encontrou-se grande comprometimento do mesmo, do córtex presubicular e do córtex entorhinal. Na avaliação microscópica destes pseudocistos, comprovou-se que estes eram compostos de líquido com restos celulares, caracterizando como uma área necrótica de substância cinzenta comprovando a MEN. Além das áreas necróticas, como diferencial para MEG, é a ausência de granulomas ou macrófagos epitelióides (CORDY, 1979).

Os achados anatomopatológicos e clínicos da MEN são similares aos reportados nos casos de ECP (BELTRAN \& OLLIVET, 2000; CORDY \& HOLLIDAY, 1989; HINRICHS et al., 1996; KOBAYASHI et al., 1994) e MEN (STALIS et al., 1995). Deste modo, relatamos o primeiro caso de MEN em um cão da raça Maltês no Brasil.

\section{AGRADECIMENTOS}

Os autores agradecem ao Serviço de Clínica Médica de Pequenos Animais e ao Serviço de Diagnóstico por Imagem do Hospital Veterinário da Faculdade de Medicina Veterinária e Zootecnia da Universidade de São Paulo (HOVET-FMVZ-USP), à Titular do Departamento de Patologia da FMVZ-USP, Prof ${ }^{\mathrm{a}}$ Dra $^{\mathrm{a}}$ Maria Lúcia Zaidan Dagli, pela leitura crítica do texto, e ao senhor Hattori Hanzo. 

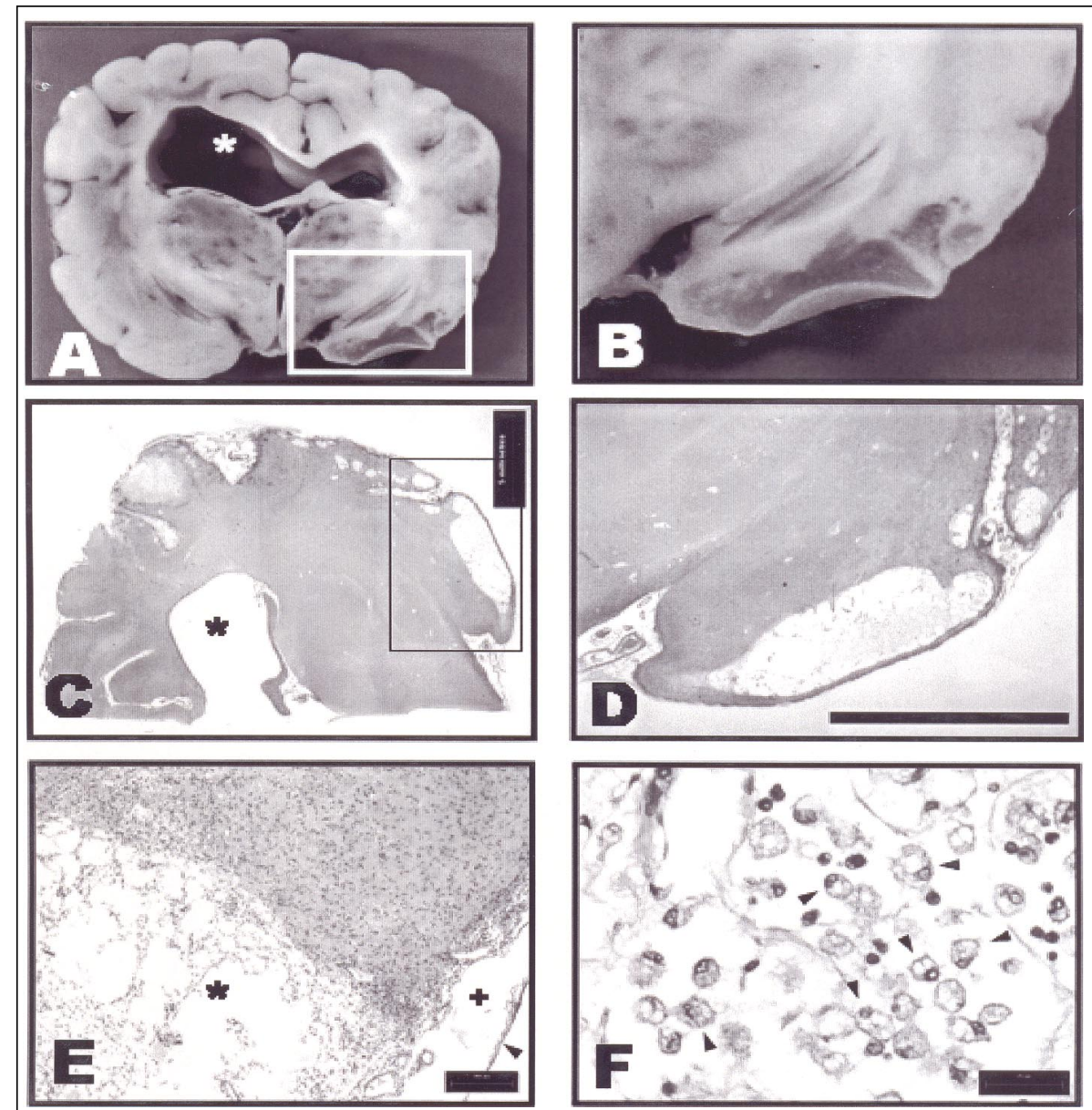

Figura 1 - A) Corte coronal do encéfalo com sistema ventricular dilatado * e detalhe de pseudocisto no quadrado branco; B) Detalhe da figura 1A, C) Dilatação ventricular indicado po *. [HE; escala da barra 5mm]; D) Detalhe da figura 1C em maior aumento. [HE; escala da barra 5mm]; E) A ponta da seta indica as Leptomeninges que estão espassadas, no espaço submeningial presença de infiltrado inflamatório e líquido indicado por +, grande área necrótica com perda celular do parênquima indicado por *. [HE; escala da barra $200 \mu \mathrm{m}$ ]; F) As setas indicam os macrófagos espomosos, em grande quantidade. [HE; escala da barra $20 \mu \mathrm{m}]$.

\section{REFERÊNCIAS}

BELTRAN, W.A.; OLLIVET, F.F. Homonymous hemianopia in a pug with necrotising meningoencephalitis. J Small Anim Pract, v.41, n.4, p.161-164, 2000.

CANTILE, C. et al. Necrotizing meningoencephalitis associated with cortical hippocampal hamartia in a Pekingese dog. Vet Pathol, v.38, n.1, p.119-122, 2001.

CORDY,D.R. Canine granulomatous meningoencephalomyelitis. Vet Pathol, v.16, n.3, p.325-333, 1979.

CORDY, D.R.; HOLLIDAY, T.A. A necrotizing meningoencephalitis of pug dogs. Vet Pathol, v.26, n.3, p.191-194, 1989.

HINRICHS, U. et al. [A case of necrotizing meningoencephalitis in a pug dog (pug dog encephalitis-PDE)]. Tierarztl Prax, v.24, n.5, p.489-492, 1996.

KOBAYASHI, Y. et al. Necrotizing meningoencephalitis in pug dogs in Japan. J Comp Pathol, v.110, n.2, p.129-136, 1994.
KUWABARA, M. et al. Magnetic resonance imaging and histopathology of encephalitis in a Pug. J Vet Med Sci, v.60, n.12, p.1353-1355, 1998.

SCHATZBERG, S.J. et al. Polymerase chain reaction screening for DNA viruses in paraffin-embedded brains from dogs with necrotizing meningoencephalitis, necrotizing leukoencephalitis, and granulomatous meningoencephalitis. J Vet Intern Med, v.19, n.4, p.553-559, 2005.

STALIS, I.H. et al. Necrotizing meningoencephalitis of Maltese dogs. Vet Pathol, v.32, n.3, p.230-235, 1995.

SUMMERS, B.A. et al. Inflammatory diseases of the central nervous system. In: St. Louis: Mosby, 1995. cap.3, p.95-185.

SUZUKI, M. et al. A comparative pathological study on canine necrotizing meningoencephalitis and granulomatous meningoencephalomyelitis. J Vet Med Sci, v.65, n.11, p.12331239, 2003.

TIPOLD, A. et al. Necrotizing encephalitis in Yorkshire terriers. J Small Anim Pract, v.34, p.623-628, 1993.

Ciência Rural, v.38, n.3, mai-jun, 2008. 